
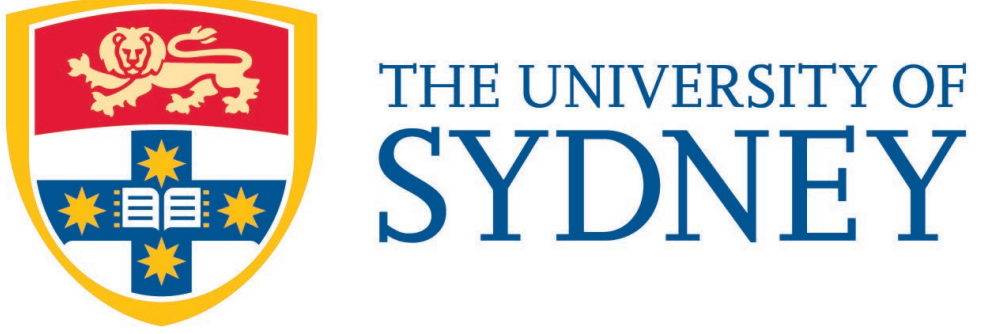

Economics Working Paper Series

$$
2019 \text { - } 15
$$

\title{
Average Inflation Targeting and Interest-Rate Smoothing
}

\author{
Yunjong Eo and Denny Lie
}

November 2019 


\title{
Average Inflation Targeting and Interest-Rate Smoothing
}

\author{
Yunjong Eo* Denny Lie $^{\dagger}$
}

November 21, 2019

\begin{abstract}
We study the welfare implication of average inflation targeting as a simple interest-rate rule, in which the monetary authority adjusts its short-term policy rate in response to the output gap as well as average inflation deviation from its target instead of reacting to the contemporaneous inflation rate as in a Taylor-type rule. We find that the welfare improvement achieved by switching to average inflation targeting from a standard Taylor rule is modest with a high degree of interest-rate smoothing, whereas it is significant without interest-rate smoothing. We show that average inflation targeting is welfare-improving in the same way as interest-rate smoothing by making the conduct of monetary policy history-dependent. Thus, the high degree of monetary policy inertia in the estimated interest-rate rules in many advanced economies implies that the welfare gain from adopting the average inflation targeting rule would be modest.
\end{abstract}

Keywords: New Keynesian model; History-dependent policy; Welfare analysis; Ramsey policy; Interest-rate rule; Monetary policy inertia;

JEL classification: E12; E32; E58; E61;

*Yunjong Eo: School of Economics, University of Sydney, NSW 2006, Australia; Tel: +61 29351 3075; Email: yunjong.eo@sydney.edu.au.

${ }^{\dagger}$ Denny Lie: School of Economics, University of Sydney, NSW 2006, Australia; Tel: +61 29036 9104; Email: denny.lie@sydney.edu.au. 


\section{Introduction}

The U.S. and other advanced economies have recently undergone several structural changes that appear to matter for the conduct of monetary policy. For example, the neutral rates of interest seem to have fallen (Kiley and Roberts (2017)), which increases the risk of the short-term policy rates hitting the effective lower bound (ELB) and complicates the stabilization policy during an economic downturn. The flattening of the Phillips curve (Kuttner and Robinson (2010), Blanchard (2016)) also makes the task of an inflation-targeting central bank harder, as inflation becomes less responsive to output fluctuations.

In response to these changes, there has been an increased interest in alternative monetary policy frameworks. An attractive alternative framework is average inflation targeting (AIT). ${ }^{1}$ Under this framework, instead of stabilizing a one-period (yearly) inflation rate around the target, the central bank aims to stabilize the average inflation rate over several periods. This implies that AIT is a history-dependent policy, in which economic agents understand that future policy actions depend on past economic conditions, in addition to current and expected future conditions.

Several studies have shown that AIT has appealing properties that could potentially mitigate the complications arising from these changes. Nessén and Vestin (2005) show that AIT influences public expectations of future policy actions and improves the short-run trade-off between inflation and output stabilization. This implies that monetary policy can still be effective even under the flattening of the Phillips curve. Mertens and Williams (2019) and Svensson (2019) show that when the ELB is binding, AIT can better anchor inflation expectations, which helps reduce the effect of ELB on the economy and improves welfare. And because AIT implies that a period of below-target inflation would be followed by a period where the central bank aims for above-target inflation, AIT can be a solution to the current persistently low-inflation environment in the U.S. economy. ${ }^{2}$

These studies on AIT in the literature, however, assume that the central bank does not engage in interest-rate smoothing. As discussed in Woodford $(2003 a, b)$, interest-rate smoothing is an example of history-dependent policy, which is a hallmark of optimal policy under commitment in the presence of forward-looking agents with rational expectations. This implies that any welfare benefit potentially arising from AIT may be minimal when interest-rate smoothing is present.

In this paper, we find that the welfare improvement from the history-dependent property of AIT almost wholly disappears once we introduce a high degree of interest-rate smoothing in central bank's behavior. We show this in the context of a small-scale New Keynesian model calibrated to the U.S. economy, where AIT is implemented through a simple interest-rate rule. (See McCallum

\footnotetext{
${ }^{1}$ As part of its 2019 review of monetary policy strategy, tools, and communications, the Federal Reserve for example is interested in the question of whether to best meet its objectives there needs to be a change in its strategy that involves "[reversing] past misses of the inflation objective" (Clarida (2019)), which is a property of average inflation targeting.

${ }^{2}$ The U.S. headline and core PCE inflation rates have been persistently below its $2 \%$ target since the issuance of the statement about the $2 \%$ target in January 2012, whereas the unemployment rate has been below the FOMC's long-run projection since the early 2016. This low inflation environment in the U.S. raises a question of whether the current framework for monetary policy is consistent with achieving the dual mandate.
} 
and Nelson (2005) for a discussion on instrument rules and actual central bank practice.) It has been empirically well-documented that central banks in U.S. and other advanced economies tend to adjust their policy rates gradually in response to changes in economic conditions. Our finding thus implies that the welfare gain from adopting average inflation targeting is minimal, at least in normal times when the ELB is not binding.

\section{Illustration with a simple policy rule}

We first illustrate the history-dependent property of interest-rate smoothing and AIT using a simple interest-rate rule where the central bank only responds to inflation deviations. In the contemporaneous one-period inflation targeting (CIT), the rule is given by

$$
\hat{R}_{t}=\phi_{R} \hat{R}_{t-1}+\left(1-\phi_{R}\right) \phi_{\pi} \hat{\pi}_{t}
$$

where $\hat{R}_{t}=\log \left(R_{t} / \bar{R}\right)$ is the nominal interest rate deviation, $\hat{\pi}_{t}=\log \left(\Pi_{t} / \bar{\Pi}\right)$ is the inflation deviation from its target, $\phi_{R} \in[0,1)$ is the degree of interest-rate smoothing, and $\phi_{\pi}$ is the inflation-feedback coefficient. Iterating backward, we have

$$
\hat{R}_{t}=\phi_{R}^{\ell} \hat{R}_{t-\ell}+\left(1-\phi_{R}\right) \phi_{\pi} \sum_{j=1}^{\ell} \phi_{R}^{j-1} \hat{\pi}_{t-j+1}
$$

for any $\ell \geq 1$. Observing (2), interest-rate smoothing $\left(0<\phi_{R}<1\right)$ imposes history-dependence on central bank's behavior: the current policy rate depends on the weighted average of past inflation deviations. This property allows the central bank to influence the public's expectations regarding future policy actions, improving the short-run stabilization trade-off.

Next, we posit under AIT, the central bank follows the rule

$$
\hat{R}_{t}=\phi_{R} \hat{R}_{t-1}+\left(1-\phi_{R}\right) \phi_{\pi} \bar{\pi}_{t, t-\ell+1}
$$

where $\bar{\pi}_{t, t-\ell+1}=\frac{1}{\ell} \sum_{j=1}^{\ell} \hat{\pi}_{t-j+1}$ is the average inflation deviation with a target window $\ell \geq 1$. The target window $\ell=1$ corresponds to CIT, while $\ell=8$, for example, corresponds to an AIT rule that aims to stabilize a 2-year (8-quarter) average inflation rate.

Consider AIT when there is no smoothing, $\phi_{R}=0$. From (3), we have

$$
\hat{R}_{t}=\phi_{\pi} \bar{\pi}_{t, t-\ell+1}=\phi_{\pi} \frac{1}{\ell} \sum_{j=1}^{\ell} \hat{\pi}_{t-j+1} .
$$

Comparing this to (2), AIT without interest-rate smoothing produces the same kind of historydependent property as CIT with smoothing, and could thus produce a comparable welfare gain.

Assume instead the central bank follows (3) with $0<\phi_{R}<1$. As $\phi_{R}$ increases, the significance 
of the average-inflation term becomes less pronounced for any given $\phi_{\pi}$. Hence, the benefit arising from the history-dependent property of AIT is potentially small when there is already a heavy dose of history-dependence arising from interest-rate smoothing. Below, we further investigate the welfare implication of AIT using a New Keynesian model calibrated to the U.S. economy.

\section{Welfare gain of AIT in a New Keynesian model}

\subsection{The model}

We consider a standard New Keynesian model along the lines of Rotemberg and Woodford (1997) and Steinsson (2003), used in Eo and Lie (2019). The model consists of optimizing households, monopolistically-competitive firms, and a central bank that conducts monetary policy using a policy rule. The economy is subject to productivity, government spending, and cost-push shocks.

Households maximize

$$
E_{t} \sum_{s=0}^{\infty} \beta^{s} \frac{\left[C_{t+s}\left(1-N_{t+s}\right)^{\gamma}\right]^{1-\sigma}-1}{1-\sigma}
$$

subject to

$$
\int_{0}^{1} P_{t}(i) C_{t}(i) d i+B_{t} \leq R_{t-1} B_{t-1}+W_{t} N_{t}+\Pi_{t}^{\text {prof }}+T_{t}
$$

where $\beta \in(0,1)$ is the discount factor, $N_{t}$ denotes labor hours, $W_{t}$ is the nominal wage, $B_{t}$

represents one-period nominal government bonds, $R_{t}$ is the nominal interest rate, $\Pi_{t}^{\text {prof }}$ denotes the proceed from firms' profits, $T_{t}$ represents lump-sum taxes, $P_{t}(i)$ denotes the price of variety $i$, and the consumption index $C_{t}$ is a CES aggregator of differentiated varieties $C_{t}(i)$ with

$$
C_{t}=\left[\int_{0}^{1} C_{t}(i)^{1 /\left(1+\theta_{t}\right)} d i\right]^{1+\theta_{t}} .
$$

Firms' average markup $\theta_{t}$ follows

$$
\log \left(\theta_{t}\right)=\left(1-\rho_{\theta}\right) \log (\bar{\theta})+\rho_{\theta} \log \left(\theta_{t-1}\right)+\varepsilon_{\theta, t}
$$

with $\varepsilon_{\theta, t} \sim$ i.i.d.N $\left(0, \sigma_{\theta}^{2}\right)$.

Each firm uses labor to produce variety $i$ using

$$
Y_{t}(i)=z_{t} N_{t}(i)
$$

where aggregate productivity $z_{t}$ follows

$$
\log \left(z_{t}\right)=\rho_{z} \log \left(z_{t-1}\right)+\varepsilon_{z, t}
$$

with $\varepsilon_{z, t} \sim$ i.i.d.N $\left(0, \sigma_{z}^{2}\right)$.

Following Calvo (1983) and Yun (1996), a fraction $\alpha \in[0,1)$ of firms are not allowed to optimally 
Table 1: Calibration: baseline model

\begin{tabular}{llllll}
\hline & Value & Description & & Value & Description \\
\hline$\sigma$ & 2.00 & preference parameter & $\phi_{R}$ & 0.80 & interest-rate smoothing \\
$\gamma$ & 3.86 & preference parameter & $\rho_{z}$ & 0.95 & persistence: productivity \\
$\beta$ & $1.04^{-1 / 4}$ & quarterly discount rate & $\rho_{\theta}$ & 0.64 & persistence: cost-push shock \\
$\bar{\theta}$ & 0.25 & steady-state price markup & $\rho_{g}$ & 0.56 & persistence: government spending \\
$\alpha$ & 0.80 & price stickiness & $\sigma_{z}$ & 0.007 & standard deviation: productivity \\
$\phi_{\pi}$ & 1.50 & inflation reaction & $\sigma_{\theta}$ & 0.115 & standard deviation: cost-push \\
$\phi_{x}$ & 0.50 & output gap reaction & $\sigma_{g}$ & 0.224 & standard deviation: government spending \\
\hline
\end{tabular}

adjust their prices at time $t$, and index their prices to the time-invariant long-run inflation target $\bar{\Pi}$. Each optimizing firm $i$ chooses an identical price to maximize

$$
\sum_{s=0}^{\infty} \alpha^{s} Q_{t, t+s}\left[\tilde{P}_{t}(i) \bar{\Pi}^{s} Y_{t+s}(i)-W_{t+s}(i) N_{t+s}(i)\right]
$$

where $Q_{t, t+s}$ is the stochastic discount factor.

The policy rule is given by

$$
\hat{R}_{t}=\phi_{R} \hat{R}_{t-1}+\left(1-\phi_{R}\right)\left[\phi_{\pi} \bar{\pi}_{t, t-\ell+1}+\phi_{x} \hat{x}_{t}\right]
$$

where $\hat{x}_{t}$ denotes the output gap defined by $\log \left(Y_{t} / Y_{t}^{*}\right)$ and $Y_{t}^{*}$ is the flexible-price level of output with a constant markup. The central bank fully and credibly commits to the policy rule (12). The assumption that the central bank implements AIT through the commitment to (12) is similar to the approach in Giannoni (2014) in the context of price-level stabilization. When $\ell=1$ the rule collapses to a standard Taylor-type rule that responds to the contemporaneous inflation deviation (i.e., CIT).

Aggregate demand is given by

$$
Y_{t}=C_{t}+G_{t}
$$

where the exogenous government spending $G_{t}$ follows

$$
\log \left(G_{t} / \bar{G}\right)=\rho_{g} \log \left(G_{t-1} / \bar{G}\right)+\varepsilon_{g, t}
$$

with $\varepsilon_{g, t} \sim$ i.i.d.N $\left(0, \sigma_{g}^{2}\right)$.

Table 1 presents the model's calibration based on the postwar U.S. economy. The calibrated values of structural parameters are consistent with those in Schmitt-Grohé and Uribe (2007). We assume the standard Taylor-rule coefficients of $\phi_{\pi}=1.5$ and $\phi_{x}=0.5$, with $\phi_{R}=0.8$ for the baseline model. This value of $\phi_{R}$ is consistent with the estimate in Smets and Wouters (2007). The driving forces for $z_{t}, G_{t}$, and $\theta_{t}$ are parameterized as in Eo and Lie (2019), resulting in the 
standard deviations of inflation, the output gap, and the nominal interest rate of $3.24 \%, 2.37 \%$, and $3.15 \%$, respectively, under CIT. These numbers match the actual moments for the U.S. economy quite well. ${ }^{3}$

\subsection{Welfare-cost measure}

To evaluate and compare various policies, following Schmitt-Grohé and Uribe (2007), we calculate the unconditional welfare cost, $\lambda$, of a given policy as the fraction of consumption that households would be willing to give up under the Ramsey policy environment to be equally well off as under the alternative policy environment:

$$
E \sum_{t=0}^{\infty} \beta^{t} U\left(C_{t}^{a}, N_{t}^{a}\right)=E \sum_{t=0}^{\infty} \beta^{t} U\left((1-\lambda) C_{t}^{r}, N_{t}^{r}\right),
$$

where $E$ is the unconditional expectation operator, and $\left\{C_{t}^{r}, N_{t}^{r}\right\}$ and $\left\{C_{t}^{a}, N_{t}^{a}\right\}$ are the statecontingent plans for consumption and labor under the Ramsey policy and under the alternative policy, respectively. The Ramsey policymaker is benevolent and maximizes households' utility in (5), subject to private-sector equilibrium conditions. We solve the model up to a second-order approximation and calculate $\lambda$ for any alternative policy.

\subsection{Welfare analysis for the calibrated model}

Figure 1 (a) plots the welfare costs of adopting the policy rule (12) as a function of the target window $\ell$ for different values of $\phi_{R}$. When $\phi_{R}=0.8$, the lowest welfare cost is achieved under $\ell=12$ (3-year average inflation), with $\lambda=0.27 \%$. This policy is welfare-improving compared to $\operatorname{CIT}(\lambda=0.31 \%)$ because stabilizing the average inflation rate over several periods improves the trade-off between inflation and output stabilization, due to its effect on inflation expectations. However, the welfare gain from adopting AIT over CIT appears to be minimal. ${ }^{4}$ It is also notable that the welfare gain of using the AIT's optimal target window over a yearly inflation target (i.e., $\ell=4$ ) is even more modest. The target window should not be too large, as a large enough $\ell$ may lead to larger fluctuations in the output gap $\hat{x}_{t}$, given the stabilization trade-off. ${ }^{5}$ Here, the welfare cost starts increasing for $\ell>12$.

A different picture emerges when the monetary authority does not smooth its policy rate (i.e., $\left.\phi_{R}=0\right)$. Here, the welfare gain of AIT relative to CIT is large: $\lambda$ is reduced from $0.43 \%$ under

\footnotetext{
${ }^{3}$ The standard deviations of CPI inflation, the CBO output gap, and the federal funds rate for the sample period of 1949:Q1 to 2008:Q4 are 3.24\%, 2.37\%, and 3.40\% respectively.

${ }^{4}$ Based on the 2018 U.S. per capita personal consumption expenditure figure of $\$ 42,752$, a $0.04 \%$ welfare gain translates to $\$ 17$ per capita per year. The gain is even smaller when we assume $\phi_{R}=0.91$, which is the optimized degree of interest rate smoothing under $\phi_{\pi}=1.5$ and $\phi_{x}=0.5$. The welfare cost is only reduced from $\lambda=0.3 \%$ under CIT $(\ell=1)$ to $\lambda=0.28 \%$ under AIT with an optimized target window of $\ell=10$.

${ }^{5}$ The utility-based welfare (loss) function in our model can be shown to depend on the fluctuations of one-period inflation deviation and the output gap. See, for example, Benigno and Woodford (2005), Steinsson (2003), and Woodford (2003a).
} 
Figure 1: Welfare costs of average inflation targeting

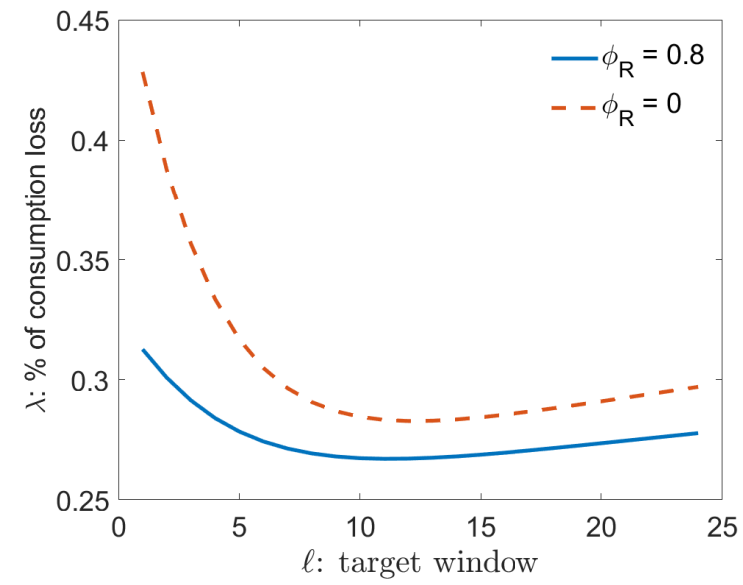

(a) interest-rate smoothing: $\phi_{R}=0.8$ vs. 0

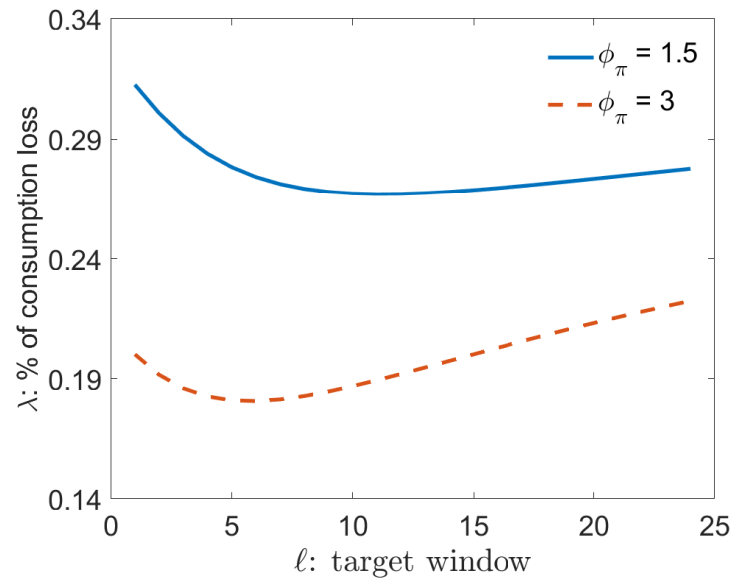

(b) inflation-feedback coefficient: $\phi_{\pi}=1.5$ vs. 3

Notes: Panel (a) plots the welfare cost $\lambda$ across different target windows $\ell$ with/without interest smoothing. Panel (b) plots the welfare cost for two different inflation-feedback coefficient values in the same way as in Panel (a). For each of cases (a) and (b), all other parameter values are set to those in Table 1 . The target window $\ell=1$ corresponds to contemporaneous (one-period) inflation targeting.

CIT to $0.28 \%$ under AIT. This finding is consistent with our discussion in Section 2: AIT could lead to a large welfare improvement due to its history-dependent property. However, when there is already a significant degree of history-dependence in central bank's behavior by way of interest-rate smoothing, there is not much benefit from adopting AIT.

The extent of the history-dependent effect of both interest-rate smoothing and AIT also depends on the inflation-feedback coefficient $\phi_{\pi}$ (see policy rules (2) and (3)). In Figure 1 (b), we instead assume $\phi_{\pi}=3$, while maintaining $\phi_{R}=0.8$. Our finding about the modest welfare gain of AIT relative to CIT still holds true. If anything, the welfare gain appears to be even smaller for this higher value of $\phi_{\pi}$.

\subsection{Alternative welfare measures}

We next assess whether our finding is robust to alternative welfare measures. Instead of (15), we use the following quadratic welfare loss function:

$$
L=\sigma\left(\hat{\pi}_{t}\right)^{2}+\lambda_{x} \sigma\left(\hat{x}_{t}\right)^{2}+\lambda_{R} \sigma\left(\hat{R}_{t}\right)^{2}
$$

where $\lambda_{x} \geq 0$ and $\lambda_{R} \geq 0$ represent the relative weight on the output-gap and the nominal interest rate stabilization, respectively; $\sigma\left(\hat{\pi}_{t}\right), \sigma\left(\hat{x}_{t}\right)$, and $\sigma\left(\hat{R}_{t}\right)$ are the standard deviations of one-period inflation, the output gap, and the nominal rate, respectively. This loss function takes into account 
Table 2: Welfare losses of various policies based on simple loss functions

\begin{tabular}{|c|c|c|c|c|c|c|c|c|c|c|}
\hline & \multirow[t]{2}{*}{$\begin{array}{c}\text { Welfare } \\
\text { cost }\end{array}$} & \multicolumn{3}{|c|}{$\begin{array}{c}\text { Model } \\
\text { standard deviations }\end{array}$} & \multicolumn{3}{|c|}{$\begin{array}{c}\text { Williams's (1999) loss function } \\
\left(\lambda_{x}=1\right)\end{array}$} & \multicolumn{3}{|c|}{$\begin{array}{l}\text { Woodford's (2003) loss function } \\
\qquad\left(\lambda_{x}=0.048\right)\end{array}$} \\
\hline & & $\sigma\left(\hat{\pi}_{t}\right)$ & $\sigma\left(\hat{x}_{t}\right)$ & $\sigma\left(\hat{R}_{t}\right)$ & $\lambda_{R}=0$ & $\lambda_{R}=0.02$ & $\lambda_{R}=0.04$ & $\lambda_{R}=0$ & $\lambda_{R}=0.077$ & $\lambda_{R}=0.154$ \\
\hline \multicolumn{11}{|c|}{ (a) interest-rate smoothing: $\phi_{R}=0.8$} \\
\hline CIT & 0.313 & 3.24 & 2.37 & 3.15 & 16.11 & 16.30 & 16.50 & 10.77 & 11.53 & 12.29 \\
\hline $\operatorname{AIT}\left(\ell^{*}=12\right)$ & 0.267 & 3.02 & 2.43 & 2.37 & 15.06 & 15.17 & 15.29 & 9.43 & 9.86 & 10.29 \\
\hline \multicolumn{11}{|c|}{ (b) no interest-rate smoothing: $\phi_{R}=0$} \\
\hline CIT & 0.428 & 3.77 & 2.03 & 7.11 & 18.35 & 19.37 & 20.38 & 14.42 & 18.31 & 22.20 \\
\hline $\operatorname{AIT}\left(\ell^{*}=12\right)$ & 0.283 & 3.14 & 2.21 & 4.72 & 14.74 & 15.18 & 15.63 & 10.07 & 11.79 & 13.50 \\
\hline
\end{tabular}

Notes: The welfare loss function has a general form of $L=\sigma\left(\hat{\pi}_{t}\right)^{2}+\lambda_{x} \sigma\left(\hat{x}_{t}\right)^{2}+\lambda_{R} \sigma\left(\hat{R}_{t}\right)^{2}$. The standard deviation $\sigma(\cdot)$ is expressed in percent (annualized for inflation and nominal interest rate). CIT and AIT refer to contemporaneous one-period inflation targeting (i.e., $\ell=1$ ) and average inflation targeting, respectively. The target window for AIT $\ell^{*}$ is chosen to minimize the welfare loss for each case with/without interest-rate smoothing.

the possibility that variations in the nominal interest rate matter for households' welfare.

We consider different values of $\lambda_{x}$ and $\lambda_{R}$, based on those used in Williams (1999) and Woodford (2003a): the former considers $\lambda_{x}=1$ and $\lambda_{R}=0.02$, while the latter uses $\lambda_{x}=0.048$ and $\lambda_{R}=0.077$, based on reasonable calibrations of a micro-founded model. We also consider a case in which the importance of nominal interest rate stabilization $\left(\lambda_{R}\right)$ is doubled.

Table 2 reports the welfare losses of CIT and AIT with the optimized target window $\ell^{*}=12$. Overall, our finding based on the measure in (15) is qualitatively robust across the two alternative welfare measures. The welfare gain, i.e., the reduction in the welfare loss, is much smaller when $\phi_{R}=0.8$ than when $\phi_{R}=0$. This is true for all three considered values of $\lambda_{R}$. The large reductions in $\sigma\left(\hat{\pi}_{t}\right)$ and $\sigma\left(\hat{R}_{t}\right)$ under $\phi_{R}=0$ are mainly responsible for the largely-reduced welfare loss under AIT. In contrast, the reductions are much smaller when $\phi_{R}=0.8$, highlighting again the minimal welfare gain from adopting AIT when there is already a large dose of history-dependent central bank's behavior arising from interest-rate smoothing.

\section{Conclusion}

We show in this paper that the welfare gain from adopting average inflation targeting over contemporaneous inflation targeting appears to be minimal when interest-rate smoothing is present. The high degree of monetary policy inertia in the estimated interest-rate rules in the U.S. and many other advanced economies implies that switching to an average inflation targeting rule would result in a modest welfare improvement.

Our analysis does not explicitly consider the possibility of a binding effective lower bound on the nominal interest rate, which may affect the welfare gain. It is also of interest to examine the robustness of our finding in a medium- or large-scale model with additional frictions in the economy. We leave them for future research. 


\section{References}

Benigno, Pierpaolo, and Michael Woodford. 2005. "Inflation stabilization and welfare: The case of a distorted steady state." Journal of the European Economic Association, 3(6): 1185-1236.

Blanchard, Olivier. 2016. "Where to from Here? The Phillips Curve: Back to the 60s?" The American Economic Review, 106(5): 31-34.

Calvo, Guillermo A. 1983. "Staggered prices in a utility-maximizing framework." Journal of monetary Economics, 12(3): 383-398.

Clarida, Richard H. 2019. "The Federal Reserve's Review of Its Monetary Policy Strategy, Tools, and Communication Problems." speech in New York, 22 February 2019, Federal Reserve Board, https://www.federalreserve.gov/newsevents/speech/clarida20190222a.htm.

Eo, Yunjong, and Denny Lie. 2019. "The Role of Inflaiton Target Adjustment in Stabilization Policy." Journal of Money, Credit and Banking, forthcoming.

Giannoni, Marc P. 2014. "Optimal interest-rate rules and inflation stabilization versus price-level stabilization." Journal of Economic Dynamics and Control, 41: 110-129.

Kiley, Michael T, and John M Roberts. 2017. "Monetary policy in a low interest rate world." Brookings Papers on Economic Activity, 2017(1): 317-396.

Kuttner, Ken, and Tim Robinson. 2010. "Understanding the flattening Phillips curve." The North American Journal of Economics and Finance, 21(2): 110-125.

McCallum, Bennett T, and Edward Nelson. 2005. "Targeting versus Instrument Rules for Monetary Policy." Federal Reserve Bank of St. Louis Review, 1(5): 597-611.

Mertens, Thomas M, and John C Williams. 2019. "Tying down the anchor: monetary policy rules and the lower bound on interest rates." FRB of New York Staff Report, 887.

Nessén, Marianne, and David Vestin. 2005. "Average inflation targeting." Journal of Money, Credit and Banking, 837-863.

Rotemberg, Julio, and Michael Woodford. 1997. "An optimization-based econometric framework for the evaluation of monetary policy." In NBER Macroeconomics Annual 1997, Volume 12. 297-361. MIT Press.

Schmitt-Grohé, Stephanie, and Martin Uribe. 2007. "Optimal simple and implementable monetary and fiscal rules." Journal of Monetary Economics, 54(6): 1702-1725.

Smets, Frank, and Rafael Wouters. 2007. "Shocks and frictions in US business cycles: A Bayesian DSGE approach." The American Economic Review, 97(3): 586-606. 
Steinsson, Jon. 2003. "Optimal monetary policy in an economy with inflation persistence." Journal of Monetary Economics, 50(7): 1425-1456.

Svensson, Lars EO. 2019. "Monetary policy strategies for the Federal Reserve." Prepared for the Cconference Monetary policy strategy, tools and communicafion pracfices-A Fed listens event, Federal Reserve Bak of Chicago.

Williams, John C. 1999. "Simple Rules for Monetary Policy." Federal Reserve Board FEDS Paper 99-12.

Woodford, Michael. 2003a. Interest and prices: Foundations of a theory of monetary policy. Princeton university press.

Woodford, Michael. 2003b. "Optimal interest-rate smoothing." The Review of Economic Studies, 70(4): 861-886.

Yun, Tack. 1996. "Nominal price rigidity, money supply endogeneity, and business cycles." Journal of Monetary Economics, 37(2): 345-370. 